\title{
Treatment rates for sea lice of Scottish inshore marine salmon farms depend on local (sea loch) farmed salmon biomass and oceanography
}

\author{
Alexander G. Murray*, Malcolm Hall \\ Marine Scotland Science Marine Laboratory, 375 Victoria Road, Aberdeen AB11 9DB, UK
}

\begin{abstract}
Sea lice are the most damaging parasite of marine-farmed salmon. Lice are controlled largely by using medicines. Discharge consents limit the allowed medicine use and hence biomass of salmon that can be farmed. The local environment may be expected to play a role in determining the frequency of application of these medicines on specific salmon farm sites. To assess this, we used data collected by the Scottish Environment Protection Agency on lice treatments and fish biomasses from 2005 to 2012 for salmon farm sites located within sea lochs (offshore sites are not included), together with local hydrographic data. There was relatively little variation in treatment rates between different sites within a loch, so a loch (or larger unit) is the appropriate area for analysis of factors influencing these treatment rates. Treatment rates tended to increase with the loch's total biomass of farmed salmon. Dependence of treatment rate on loch flushing time was highly significant in all regions; however, dependence was positive in the Northern and Western Isles but negative in mainland Scotland. A possible explanation is flushing of lice away from island sea lochs but into mainland sea lochs, in line with prevailing currents. Regional variation in dependence suggests that oceanographic processes at larger spatial scales play a significant role in determining lice dynamics.
\end{abstract}

KEY WORDS: Sea lice treatment · Generalised linear model · Salmon aquaculture

\section{INTRODUCTION}

Sea lice are copepod ectoparasites of fish that annually cost salmonid farming €33 million in Scotland and $€ 300$ million worldwide (Costello 2009). In Scottish salmon farms, the main problem species is Lepeophtheirus salmonis, a salmonid specialist (Pike \& Wadsworth 1999), whilst the generalist Caligus elongatus is less of a problem (although elsewhere, Caligus species cause serious problems on salmon farms, e.g. C. rogercresseyi in Chile; Valdes-Donoso et al. 2013). The planktonic larval phases of sea lice (2 naupliar stages and the infectious copepodid stage) are transmitted by water movements that can lead to infection pressure at distances of several kilometres from their source (Middlemas et al. 2013,

\footnotetext{
${ }^{*}$ Corresponding author: sandy.murray@scotland.gsi.gov.uk
}

Salama et al. 2013). Generation times are temperature-sensitive; at $10^{\circ} \mathrm{C}$, they are $40 \mathrm{~d}$ for male and $52 \mathrm{~d}$ for female lice (Pike \& Wadsworth 1999). Because of hydrodynamic transmission, infection pressure on a particular site may be expected to depend on the biomass of fish not only of that site but also of other sites in the vicinity (Adams et al. 2012, Jansen et al. 2012, Aldrin et al. 2013).

The Scottish coast (Fig. 1) contains a large number of small fjordic systems known as voes (in Shetland) or sea lochs (elsewhere in Scotland). These systems are naturally self-contained areas, and their basic hydrographic features (such as area and tidal elevation) have been catalogued and described by oceanographers for decades (Edwards \& Sharples 1986). Temperatures in these enclosed systems are variable

(C) The Crown 2014. Open Access under Creative Commons by Attribution Licence. Use, distribution and reproduction are unrestricted. Authors and original publication must be credited. 


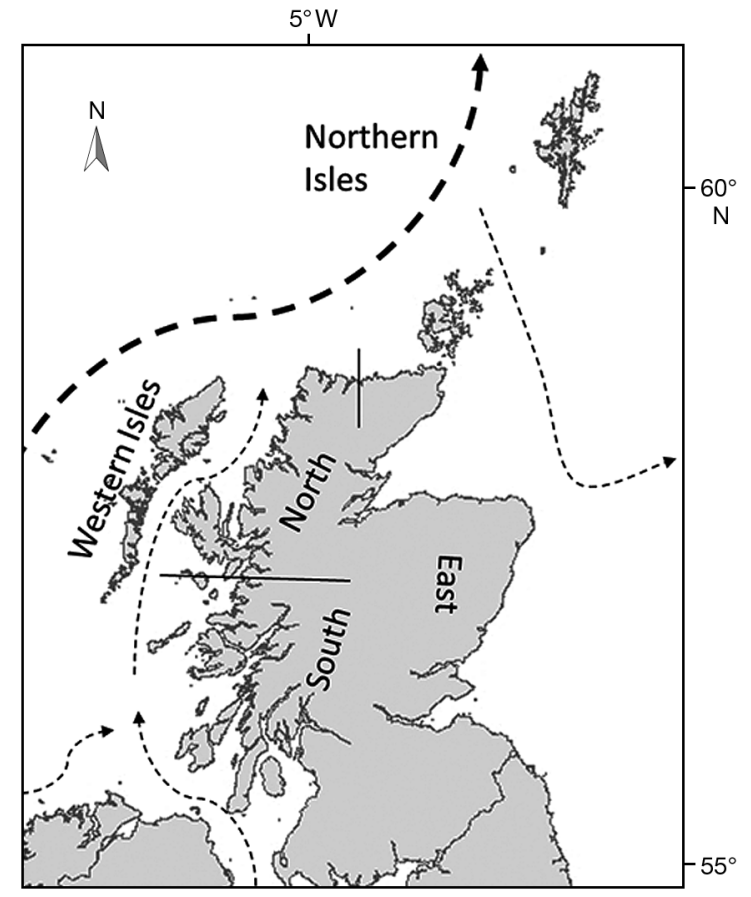

Fig. 1. Map of Scotland showing prevailing ocean current (thick dashed line) and coastal currents (thin dashed lines); see Baxter et al. (2011) for more details. For model analyses, the country is divided into Northern Isles, Western Isles, and northern and southern mainland regions (an east mainland region lacks marine salmon farms). The many small inlets in these regions (lochs and voes) form the units for analysis that are detailed in MSS (2013)

but may range from $4^{\circ} \mathrm{C}$ in winter to $16^{\circ} \mathrm{C}$ in summer, and because most Scottish rivers flow eastward, freshwater input is relatively low and salinity is generally fairly high in most sea lochs (Murray et al. 2011). Although many farm sites are not located in these systems, the lochs are defined by geography and oceanography, and often by co-operative management, and so are natural units to assess how local environmental factors influence lice treatment of fish sites.

Sea lice control is carried out largely using a variety of medicines (Grant 2002), although other methods, such as the use of cleaner fish, are also applied (Treasurer 2002). The Scottish Environment Protection Agency (SEPA) collects data on the biomass of fish in marine sites and the monthly doses of treatments used to control sea lice as a part of its regulatory function. Treatment reflects the effort the sites need to control lice and therefore is a function of infection pressure; treatment frequency increases with lice abundance (Revie et al. 2003). The level of lice control may also be a function of local management practices; however, national treatment thresholds are specified in a code of good practice that cov- ers $95 \%$ of Scottish salmon production (CoGP 2013). Increased need to use medicines may select for resistance that undermines the effectiveness of such medicines, and emergence of resistance may be selected for by incomplete treatments (Murray 2011). Residues in the environment could have effects on wild invertebrates (Mayor et al. 2008). To keep concentrations within defined safe limits (Willis et al. 2005), SEPA restricts the maximum biomass that can be held on each site. Identification of circumstances under which treatment consents are most likely to be exhausted is therefore important for the sustainable growth of aquaculture.

Generalised linear models (GLM) and the related generalised linear mixed models (GLMMs) are widely used to identify the dependence of variables of interest on risk factors (Nelder \& Wedderburn 1972, McCulloch \& Searle 2001). These models have been widely applied to identify risk factors associated with salmon lice numbers, for example in Scotland (Revie et al. 2003), Chile (Kristoffersen et al. 2013, ValdesDonoso et al. 2013), and Norway (Jansen et al. 2012, Aldrin et al. 2013). These models allow the identification of those factors that are most likely to be associated with a response variable, but they do not identify causality. Here, for the first time, we apply such models to analyse the environmental factors associated with sea lice treatment regimes. These models give an insight into incidence of infection because the treatment variable is a rate. However, treatment practices might vary regionally, and it is possible that the association between lice infection and treatment rate could also vary. The length and size of the data set and the availability of co-located hydrographic data allow a detailed analysis of the association of treatment with local environment, including the variation between regions in associations. We initially hypothesised that small lochs with large biomass and low turnover rates would have the highest treatment rates.

\section{METHODS}

The SEPA data were available for the 91 mo period from January 2005 to September 2012. These data include the monthly doses of 5 medicines (deltamethrin [Alphamax], cypermethrin [Excis], azamthiphos [Salmosan], emamectin benozoate [Slice] or teflubenzuron [Calicide]) used to treat lice on each marine fish farm in Scottish waters. The data are collected to protect against environmental contamination, so the use of hydrogen peroxide (which breaks 
down to oxygen and water) is not included nor are alternative lice controls such as the use of wrasse to eat lice (Treasurer 2002). The monthly biomass at each site over this period is also extracted from this SEPA database.

Additional data were obtained for treatments carried out in well boats that began to be licenced from 2009. Fish are taken into the wells of a well boat and treated in this confined and regulated space, allowing a more efficient application of the active ingredients. Data were obtained for these treatments for 2010 to 2012 as additional treatments that were added to the on-site treatments listed by SEPA. Daily treatment records were used to identify the number of individual months in which treatments occurred. Hydrogen peroxide treatments that are included in this data set are excluded from the analysis since similar treatments are not included in the SEPA data. The number of well-boat treatments was small and only accounted for $\sim 1 \%$ of the SEPA listed treatments for the site located within the lochs analysed.

The treatment data are used in this paper to categorise, for each site, all months as either 0 if no treatment occurred or as 1 if treatment did occur. Treatment occurred if any of the listed medicines had a monthly dosage recorded as $>0$ at the site. Sites are treated as the units for lice management, with approved lice counts being statistically designed to establish abundance and prevalence at the site, rather than cage, level (CoGP 2013). The fact of a site not being treated is not meaningful if there are no fish on that site, so a second categorisation is made in which a site is treated as occupied (1) if biomass $>0$ or as not occupied (0) otherwise. Sites that mainly, or exclusively, farmed fish other than salmon (cod, halibut and trout) were excluded from this analysis; however, it is possible that some of the biomass was of these species on a few sites for short periods. Each site has a monthly treatment rate $C_{\mathrm{S}}$ calculated as the sum of months with treatment divided by the sum of months occupied over the period January 2005 to September 2012. Similarly, an average site biomass, $B_{\mathrm{S}}$, is calculated by dividing the sum of monthly biomasses recorded on the site by the number of months the site was occupied. Observations from 9730 mo are used to calculate these variables for 192 salmon sites located within lochs in the catalogue. A further 122 salmon farming sites located outwith the catalogued lochs are not included in this analysis. The analysed sites in the lochs were subjected to 2749 on-site treatment events plus 26 well-boat treatments, making a total of 2775 mo with $\geq 1$ treatment events.
The hydrographic properties of individual lochs were catalogued by Edwards \& Sharples (1986). This catalogue, together with SEPA biomass data, is used by the official Fisheries Research Services (now Marine Scotland) to derive guidelines for acceptable environmental impacts for sites in a given loch (Gillibrand \& Turrell 1997). For this reason, values have been updated as improved information becomes available (MSS 2013). The flushing time $\left(T_{\mathrm{f}}\right)$ is the time taken for a loch to exchange $60 \%$ of its water with the outside environment. This is calculated as $T_{\mathrm{f}}=1.05 V_{\mathrm{LW}} /\left[\left(A_{\mathrm{LW}}+A_{\mathrm{HW}}\right) \times 0.7 R_{\mathrm{T}}\right]$ (Gillibrand \& Turrell 1997) where $V_{\mathrm{Lw}}$ is the loch volume at low water, $A_{\mathrm{LW}}$ is the area at low water, $A_{\mathrm{HW}}$ is the area at high water, and $R_{\mathrm{T}}$ is the tidal range.

The average loch-level treatment rate, $C_{\mathrm{L}}$ is calculated by dividing the sum of all the observed treatment events by the number of months of occupation across all the sites in a given loch. Loch average biomass, $B_{\mathrm{L}}$ is also calculable, but is slightly more complex. For each of the 91 mo in the data set, the total biomass in that mo on all sites in the loch, $B_{\mathrm{Lt}}$, is multiplied by the number of sites in the loch that have biomass $>0$ on site in that month, $S_{\mathrm{Lt}}$ this result is then divided by the sum of $S_{\mathrm{Lt}}$ for all months.

$$
B_{\mathrm{L}}=\frac{\sum_{t=1}^{91} B_{\mathrm{Lt}} S_{\mathrm{Lt}}}{\sum_{t=1}^{91} S_{\mathrm{Lt}}}
$$

This weighting formula corrects for the pattern of site occupation, so if 2 sites were occupied concurrently, $B_{\mathrm{L}}$ is higher than if they were occupied sequentially and is the actual loch average biomass to which occupied sites are exposed. Data from the 192 marine salmon sites within lochs are used to calculate these parameters for 81 lochs. However, in 3 lochs, no site was occupied for a full year, and these lochs were excluded because site and loch level treatment rates based on so few data were potentially subject to excessive stochastic variation. This left 188 sites in 78 lochs for analysis of variation between lochs. The full 192 sites and 81 lochs are used to provide data for a GLM analysis of treatment risk factors.

Variation between treatment rates at different sites in the same loch is assessed. This variation is important for management as similarity of treatment rates demonstrates lice management is required to be at the loch, or higher, level to be effective. It also gives evidence as to the likely treatment requirements of any new sites placed in the loch. If sites within lochs do not have similar treatment requirements, then the loch-level characteristics cannot have much influence on treatment rates. Similarity in treatment 


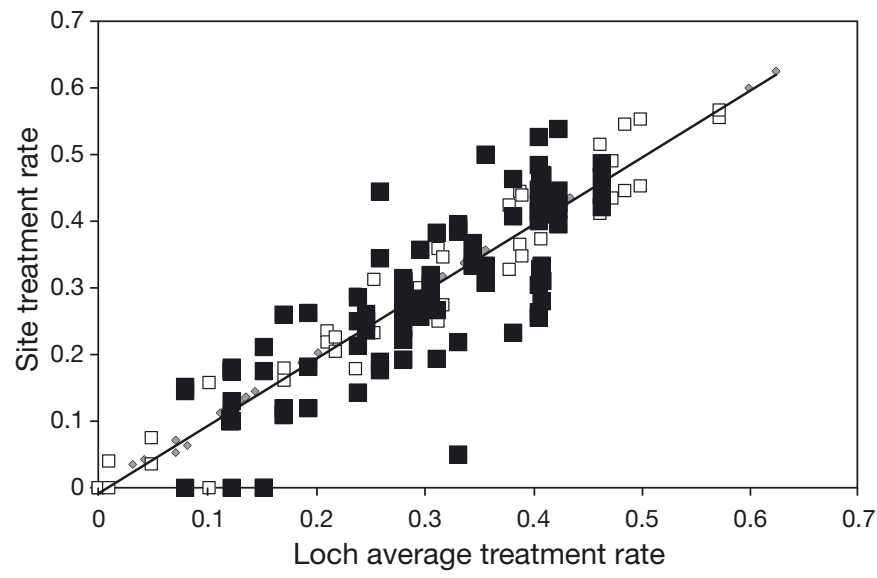

Fig. 2. Treatment rate of sites versus loch treatment rate averaged over all sites in Scottish sea lochs (Fig. 1). Small diamonds: lochs containing only one site; white squares: lochs containing only 2 sites; black squares: lochs containing $>2$ sites. Sites occupied for $<1 \mathrm{yr}$ are excluded

rates might have been forced on sites with different treatment requirements, but in fact, area management agreements (AMAs) only became legal requirements under the 2013 Aquaculture and Fisheries Act (Scotland). Since it was not legally required, coordinated management achieved during the period of analysis was on a voluntary basis and so reflected farmers' own experience that co-ordination was in their best interests. The site-level and loch-level treatment rates are compared to assess the importance of properties at these 2 levels for assessing the site level.

The differences between loch-level treatment rates for different lochs are used to assess the fundamental associations of loch characteristics (hydrographics and loch-level biomass) with observed treatment rates for lice. Larger-scale regional patterns are also analysed using the regional location of the loch.

The regions used for analysis are defined as the Western Isles (outer Hebrides), the Northern Isles (Orkney and Shetland), and northern and southern mainland regions (including the inner Hebrides), the boundary being defined by the northern boundary NN and NM and the southern boundary of NG and $\mathrm{NH}$ of the Ordnance Survey's $100 \mathrm{~km}$ grid squares (Fig. 1). No marine salmon sites are currently active off the east coast of Scotland. The Northern Isles are used as the baseline region for analysis of variation between the regions. The Northern Isles contained 65 sites in 27 lochs; the Western Isles contained 49 sites in 17 lochs (of which 2 lochs, each containing 1 site, were excluded); the north mainland contained 43 sites in 24 lochs $(1$ loch containing 2 sites ex- cluded); and the south mainland contained 35 sites in 13 lochs. Exclusion occurred, as described, when no site in the loch was occupied for $>1 \mathrm{yr}$.

The data are used to develop models of treatment events, per month of occupation, for all sites in a loch relative to loch environmental properties. A series of models is developed to assess dependence of the treatment rate on loch properties, starting with a complex model including a larger range of variables (loch area, volume, length, average biomass, number of sites and region in which the loch was located). Modelling is carried out using the R statistical environment (Venables \& Smith 2013). Terms associated with a $\mathrm{p}$ value of $>0.05$ are dropped from the model.

\section{RESULTS AND DISCUSSION}

Our main interest is in being able to identify, and if possible explain, what environmental factors influence a site's rate of treatment. Sites characterised by a higher value of $C_{\mathrm{S}}$ are likely to experience more problems with sea lice than sites characterised by a lower value of $C_{\mathrm{S}}$ (Jansen et al. 2012). This may be biased if sites with more active lice-management regimes are treated more frequently than other sites. There are nationally defined levels of adult female lice per salmon (1 July to January, 0.5 February to June) at which treatment should be considered (CoGP 2013). This does not mean that lice levels are always kept below these levels, and differences in local treatment rates might, at least in part, be due to local control practices; however, it does mean treatment regimes in different regions have broadly similar objectives. Generation times, from egg to ovigerous female, are generally greater than the monthly intervals at which treatments are recorded. However, in warm summer conditions, it is possible a generation could be achieved within a month (Pike \& Wadsworth 1999).

Only treatments using medicines are considered in this analysis. While alternative treatments do exist, such as the use of wrasse to eat lice (Treasurer 2002), they have typically been used in a small minority of cases. Although they have been available for many years, wrasse use is only now becoming more widespread as technical and infrastructure issues, such as availability from hatcheries, are solved. Even within the list of medicines, the use of hydrogen peroxide is not documented in the SEPA data set. Hydrogen peroxide can be used without leaving residues in salmon flesh, and therefore, it may be used for late treatments near harvest. We have no reason to believe 


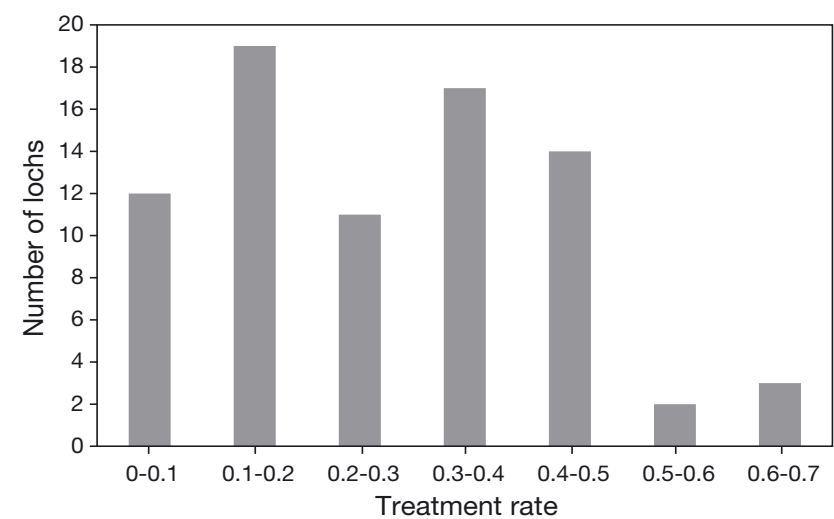

Fig. 3. Distribution of average rates of sea lice treatment between lochs

that its exclusion biases the analysis of the treatment rates' association with the environmental factors considered here, although it will lead to underestimation of the frequency of treatment. The lack of this hydrogen peroxide data is a gap in the analysis that must be borne in mind when considering the results; however, because it does not produce environmental residues, its use is not relevant in determining whether the treatment applications approach environmentally acceptable limits.

\section{Modelling of treatment of sites within lochs}

If $C_{\mathrm{S}}$ is plotted against $C_{\mathrm{L}}$ for the loch in which the site is located, then the level of scatter is very limited with a coefficient of determination $\left(\mathrm{r}^{2}\right)$ of 0.85 (Fig. 2). Of course, if there is only one site in a loch, its treatment rate will be exactly the same as the loch average $\left(C_{\mathrm{S}}=C_{\mathrm{L}}\right)$. However, even if lochs containing only 1 or 2 sites are excluded, the relationship remains strong, with $\mathrm{r}^{2}$ values of 0.79 and 0.68 respectively. This co-relation is high given that different sites in a loch are often occupied for different time periods. Sites occupied for $<1 \mathrm{yr}$ are excluded from this analysis as stochastic variation will drive variance in treatment rates for such sites.

The relative importance of the variation between lochs, with respect to that within lochs, can be estimated using a GLMM. The model used assumes a binomial error distribution, utilising a logit-link function, and fits the intercept as a fixed effect while lochs and sites within lochs are fitted as random effects. The variance components of $0.893 \pm 0.945$ for variation between lochs and $0.007 \pm 0.082$ for variation between sites within lochs indicate that a large majority of the variation $(99 \%)$ can be ascribed to differences between lochs. Indeed, there is no evidence that the addition of sites within lochs improved the model fit $\left(\chi^{2}{ }_{1}=0.16, p>0.05\right)$.

Treatments are increasingly co-ordinated across areas as part of AMAs. Membership of an AMA is now a legal requirement under the Aquaculture and Fisheries Act (Scotland) 2013. Although this legal obligation did not apply for the period analysed, coordination was still widespread in practice. Such coordinated management practices will drive similar treatment regimes on different sites in a loch, but the use of this practice (without legal requirement) in itself implies an expectation of co-ordinated outbreaks. Exchange of lice between sites occurs through hydrodynamic mixings (Salama et al. 2013), and while $66 \%$ of infection pressure on a site originates from within a site, $28 \%$ is from other sites in the neighbourhood (with 6\% from other sources) (Aldrin et al. 2013). This substantial exchange of larval lice between sites leads to co-ordination in the development of lice epidemics on different sites. The lack of site-level effects found here for treatment rate does not preclude the possibility that certain sites play different roles in seeding outbreaks across lochs, acting as sinks or sources (Adams et al. 2012). Infection may initially develop at different rates on different sites, but the development of elevated lice loads at one site will lead to problems for its neighbours. This means that the loch is a more appropriate focus for analysis of risk factors than is site, and subsequent analysis was carried out on lochs.

\section{Variation between lochs}

Among the 78 lochs analysed (excluding the 3 that contained no sites occupied for at least $1 \mathrm{yr}$ ), treatment rates range from 0 to $0.625 \mathrm{mo}^{-1}$. In general, the rates are fairly evenly distributed over the range 0 to $0.5 \mathrm{mo}^{-1}$, with smaller numbers of lochs $(6.3 \%)$ subject to treatment rates of 0.5 to $0.625 \mathrm{mo}^{-1}$ (Fig. 3).

The continuous variables all show a characteristic relationship with treatment rate in that low values of loch area, loch volume, loch length (not shown), flushing time, and biomass are all associated with treatment rates that are either very high or very low, while larger values are associated with intermediate treatment rates (Fig. 4). The result in all these cases is a distribution of treatment rates that resembles a rotated Y. There is a general trend for loch-level treatment rate to increase with biomass (Fig. 4D) and to decrease with flushing time (Fig. 4C) within the tail of the Y (i.e. for moderate or higher values of the independent variable). Associations of treatment rate 

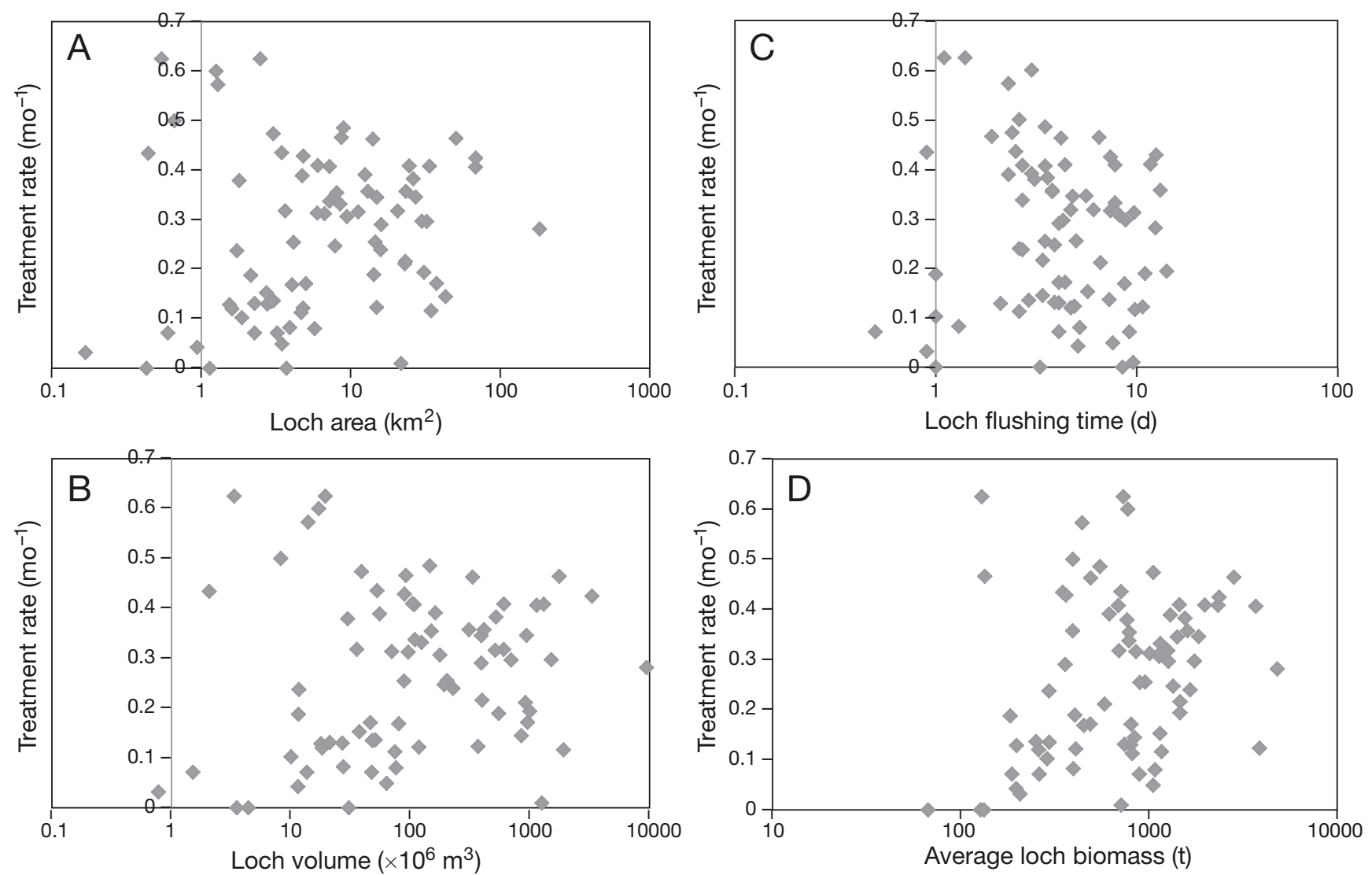

Fig. 4. Univariate associations of loch-level parameters (A: area; B: volume; C: flushing time; D: loch biomass) with lochlevel treatment rates

with loch area, volume, and length are weak but positive in their tails.

Variation between lochs has, to this point in the analysis, been assumed to be randomly distributed; however, treatment rates differ between the regions of analysis (Fig. 5). The assignment of lochs to these fixed regions results in an improved model fit $\left(\chi^{2}{ }_{12}=\right.$ $25.9, \mathrm{p}=0.011)$ when subjected to a GLMM, assuming a binomial error distribution. This result indicates that treatment rates vary between regions in a non-random manner; the implications of this regional variation will be discussed later.

\section{Modelling differences in treatment rates between lochs}

Treatment rates at the loch level can be modelled as a function of loch hydrodynamics and loch-level biomass. Since there are spatial variations in dependence, the model was fitted against the terms and their interaction with region; the Northern Isles was the default baseline region. A fixed effects GLM was developed, assuming a binomial error distribution, utilising data grouped at the loch level and modelling the variation between lochs within regions as overdispersion. This GLM was fitted by the stepwise omission of explanatory variables that were not sta-

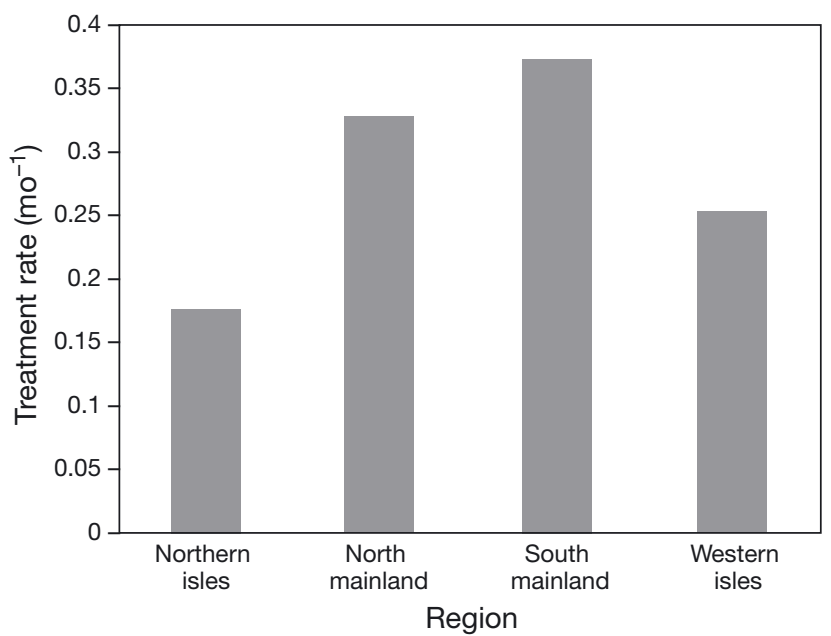

Fig. 5. Sea lice monthly treatment rates by region (regions as defined in Fig. 1) 
tistically significant, producing the following final model:

$$
\begin{aligned}
\ln [P /(1-P)]= & \beta_{0}+\beta_{1} T_{\mathrm{f}}+\beta_{2} V_{\mathrm{L}}+\beta_{3}\left[\ln \left(B_{\mathrm{L}}\right)\right] \\
& +\beta_{4} R+\beta_{5} R \cdot T_{\mathrm{f}}+\beta_{6} R \cdot V_{\mathrm{L}}
\end{aligned}
$$

where $\beta_{0}$ is the intercept, $T_{\mathrm{f}}$ is the loch flushing time as a continuous variable, $V_{\mathrm{L}}$ is the loch volume as a continuous variable, $B_{\mathrm{L}}$ is the mean loch biomass as a continuous variable, and $R$ is region as a categorical factor. Since we are not modelling individual sites or lochs, but rather the general probability of treatment, the sites with $<1$ yr occupancy are also used; therefore, all 192 sites from 81 lochs are included. The potential explanatory variables of loch length, area, and number of active sites (with associated interactions) did not improve the fit of the model. These variables are correlated with the variables that are included in the model, and associations may be confounded by this correlation. Results from the model, which incorporates an overdispersion correction parameter of 6.38, are presented in Table 1.

Diagnostic plots of the residuals from this model indicate that data for 2 of the lochs exert excessive leverage. Conversion of continuous values to quartiles reduced this leverage to acceptable values and resulted in the omission of loch volume and its interactions from this model (Table 1). Likewise, analysis of the binary data using a GLMM incorporating loch within regions as a random effect and the conversion of the continuous values to quartiles resulted in the inclusion of the explanatory variables listed above but omission of loch volume and its interactions. The inclusion of loch volume in the continuous model is likely because a few large lochs contained many sites and hence many observations; this gives these large lochs disproportionate leverage on the results.

The model results indicate that there is a consistent positive association, across all regions, between the monthly probability of treatment of sites and the total biomass of farmed salmon in an area. This relation is robust to analysis using raw data or data clustered into quartiles. Revie et al. (2003) found that Lepeophtheirus salmonis abundance was not influenced by site biomass or presence of sites within $5 \mathrm{~km}$ that were not members of an AMA. We find that treatment associates with loch-level biomass rather than site-level biomass. Possibly, the hydrographically defined lochs are more informative of interactions among sites than the $5 \mathrm{~km}$ distance used by Revie et al. (2003). In Norway (Jansen et al. 2012, Aldrin et al. 2013) and Chile (Kristoffersen et al. 2013, ValdesDonoso et al. 2013), sea lice loads do reflect infection pressure from sites in the vicinity, but the pattern of
Table 1. Model coefficients using continuous (left column) or quantised (quartiles; right column) data ( $\pm 1 \mathrm{SE}$ ). The optimal quantised model excludes loch volume, and so its significance and regional interactions are not applicable (N/A). $T_{\mathrm{f}}=$ loch flushing time; $V_{\mathrm{L}}$ : loch volume; $B_{\mathrm{L}}$ : loch biomass; WI: Western Isles. Statistical significance: ${ }^{*} 0.01<\mathrm{p} \leq 0.05$; ${ }^{* *} 0.001<\mathrm{p} \leq 0.01 ;{ }^{* * *} \mathrm{p} \leq 0.001$

\begin{tabular}{|lcc|}
\hline Coefficient & $\begin{array}{c}\text { Estimate } \\
\text { (continuous) }\end{array}$ & $\begin{array}{c}\text { Estimate } \\
\text { (quartiles) }\end{array}$ \\
\hline Intercept & $-4.90 \pm 0.86^{* * *}$ & $-3.90 \pm 0.66^{* * *}$ \\
$T_{\mathrm{f}}$ & $0.18 \pm 0.04^{* * *}$ & $0.53 \pm 0.18^{* *}$ \\
$V_{\mathrm{L}}$ & N/A \\
$\ln \left(B_{\mathrm{L}}\right)$ & $-1.59 \pm 0.62^{*}$ & $0.22 \pm 0.07^{* *}$ \\
Region (Northern Isles $=$ baseline) & \\
North & $2.94 \pm 0.45^{* * *}$ & $3.48 \pm 0.72^{* * *}$ \\
South & $2.87 \pm 0.51^{* * *}$ & $3.97 \pm 0.79^{* * *}$ \\
WI & $0.86 \pm 0.56$ & $1.84 \pm 0.74^{*}$ \\
$\boldsymbol{T}_{\mathrm{f}} \times$ Region interaction term (Northern Isles $=$ baseline) \\
$T_{\mathrm{f}} \times$ North & $-0.48 \pm 0.10^{* * *}$ & $-0.92 \pm 0.22^{* * *}$ \\
$T_{\mathrm{f}} \times$ South & $-0.34 \pm 0.09^{* * *}$ & $-0.99 \pm 0.23^{* * *}$ \\
$T_{\mathrm{f}} \times$ WI & $0.07 \pm 0.15$ & $-0.26 \pm 0.25$ \\
$\boldsymbol{V}_{\mathrm{L}} \times$ Region interaction term (Northern Isles $=$ baseline) \\
$V_{\mathrm{L}} \times$ North & $1.91 \pm 0.63^{* *}$ & N/A \\
$V_{\mathrm{L}} \times$ South & $1.61 \pm 0.62^{*}$ & N/A \\
$V_{\mathrm{L}} \times$ WI & $1.54 \pm 0.68^{*}$ & N/A \\
\hline
\end{tabular}

linkage will depend on local hydrodynamics (Adams et al. 2012).

There is, however, a statistically significant additive association between differences in treatment rates and regions, with the 2 mainland areas having a higher treatment rate than the baseline (the Northern Isles), while the Western Isles deviance is not significant. This is somewhat different from the univariate analysis that showed treatment rates in the Western Isles to be somewhat higher than the Northern Isles (Fig. 5). Treatment rates under both GLM and univariate analyses are substantially lowest in the Northern Isles; it is possible this could indicate different treatment practices rather than lower lice abundance. Substantial mortalities were attributed to lice prior to detection of an outbreak of infectious salmon anaemia in Shetland in 2008 to 2009 (Murray et al. 2010), which contrast with the generally low mortalities attributed to lice from a data set excluding Shetland (Soares et al. 2011).

There appear to be contrary regional responses to flushing time. $T_{\mathrm{f}}$ is significantly associated with treatment rate for the baseline (Northern Isles region); this means that sites in systems with longer flushing times require more frequent treatment. Flushing time is also positively associated with treatment rate in the Western Isles. A positive association of site L. salmonis abundance with flushing time was found by Revie 


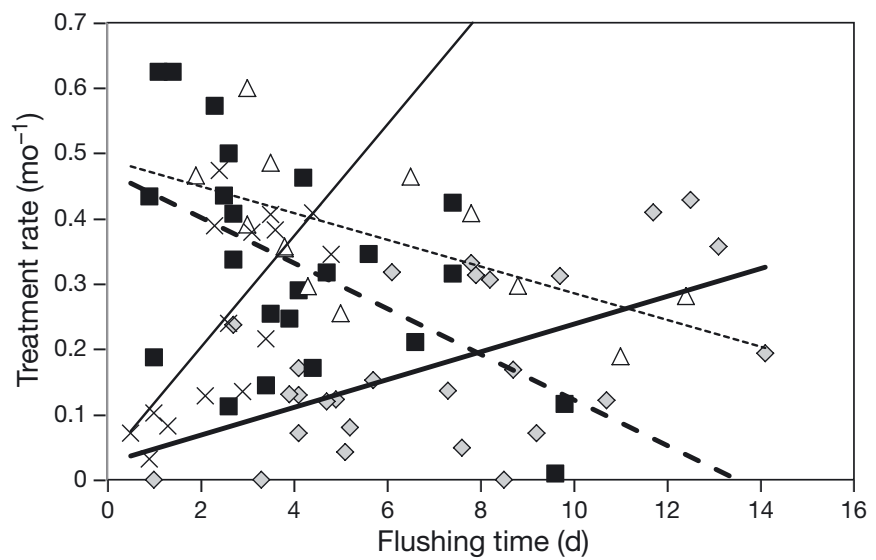

Fig. 6. Associations of sea lice treatment rates with loch turnover times subdivided by region (see Fig. 1). Grey diamonds: Northern Isles (thick solid trend $=0.02, r^{2}=0.31$ ), crosses: Western Isles (thin solid trend $=0.085, \mathrm{r}^{2}=0.52$ ), solid squares: north mainland (thick dashed trend $=-0.02$, $\mathrm{r}^{2}=0.28$ ), and white triangles: southern mainland (thin dashed trend $=-0.03, \mathrm{r}^{2}=0.36$ ). Trends are with respect to flushing time of the loch

et al. (2003). However, in our analysis, the mainland regions show strong negative associations of $T_{\mathrm{f}}$ with treatment; that is to say, the longer it takes to flush the loch, the less frequently sites within it require treatment. The 2 mainland regions have very similar negative deviations with similar very high statistical significance. We illustrate the interaction between Region and $T_{\mathrm{f}}$ by plotting $C_{\mathrm{L}}$ against $T_{\mathrm{f}}$ subdivided by Region (Fig. 6).

The association of treatment rate and flushing time may reflect the orientation of lochs with respect to prevailing north-east currents along the west coast of Scotland (Fig. 1). These currents would tend to remove lice from lochs that tend to face east in the Western and Northern Isles while trapping them in lochs on the west coast, which tend to face west. Accumulation of freshwater might also occur in lochs with long flushing times, and this would reduce lice viability; however, freshwater inputs into the sea lochs are generally relatively small (Murray et al. 2011).

The positive and negative associations with $T_{\mathrm{f}}$ are not simply determined by regional location. There are some rapidly flushed lochs in the western isles that have high treatment rates and also some rapidly flushed lochs in the northern mainland with low treatment rates (Fig. 6). This may reflect loch local aspects. An example of low treatment rates in a rapidly flushed mainland loch is in Loch Ewe, which faces north and therefore away from the prevailing currents. However, individual local circumstances may explain individual local cases; for example, relatively low salinities in Loch Ewe might control larval lice there. However, even in Loch Ewe, the measured salinities are rarely below 30\% (Baxter et al. 2011), the level that may be damaging to sea lice (Pike \& Wadsworth 1999). Isolation of the probable hydrodynamic and neighbourhood factor(s) associated with these mainland or island regions that drives this switch from high to low treatment rates in lochs with low turnover would greatly improve model fit and explanatory power.

\section{CONCLUSIONS}

We provide the first analysis of lice treatment regimes, as opposed to lice numbers. Lice treatment regimes are statistically highly significantly related to local loch properties, particularly with the logarithm of loch biomass and loch flushing time and possibly with volume. However, the relationships with the hydrographic variables were complex with a strong spatial interaction such that relationships with flushing times are qualitatively different between mainland and island Scotland. It is only because of the large quantity of data that such complex interactions could be analysed. It must be remembered that these data were collected for regulatory purposes and exclude other control mechanisms, including application of hydrogen peroxide, although there is no information to suggest this exclusion would explain associations obtained in this analysis.

The SEPA data allow assessment of sea lice treatment for sites located within lochs in all regions of Scotland. An analysis of Lepeophtheirus salmonis abundance within a commercial database was carried out by Revie et al. (2003), but this analysis used only one company's data, and this restriction limited its use for assessing interactions between sites that may belong to different companies. In Norway, the association between sites has been modelled using a fixed kernel distance (Jansen et al. 2012); here, the use of sea lochs allows local oceanographic features to explicitly define the sets of interacting sites (although this does limit the analysis to inshore sites).

For management purposes, the sites within a particular loch all exhibit similar treatment regimes. Therefore, the treatment regimes of existing sites in a loch may be a good guide for expected treatment rates for any new sites established in these lochs. Opening new sites will increase loch-level biomass and is likely to lead to an increased treatment rate for all sites in the loch. However, lochs with large existing biomass values may be those that have been 
found to tolerate such high biomasses. Therefore an increase in loch biomass may have a greater effect on site treatment rates than the modelled logarithmic increase.

Lice epidemiology appears to be driven by hydrodynamic processes within and outside lochs. The simple overall approaches used here can provide a general pattern, but specific behaviours in individual lochs may require descriptions using more complex coupled models (Adams et al. 2012, Salama et al. 2013), and larger-scale hydrodynamic modelling at the Scottish coast scale would likely be very useful to assess risk factors of individual lochs for exposure to infestation, particularly for mainland lochs. Similarly, treatment rates in other countries will be affected by their oceanographic environments.

Acknowledgements. We thank the Scottish Environmental Protection Agency for the provision of their treatment and biomass data, Anna Donald of MSS Fish Health Inspectors for locational and hydrodynamic data and Mike Bland of Marine Scotland Policy Licencing for provision of data on well-boat discharges. This work was funded by the Scottish Government through projects SP0060 and AQ0040.

\section{LITERATURE CITED}

Adams T, Black K, MacIntyre C, MacIntyre I, Dean R (2012) Connectivity modelling and network analysis of sea lice infection in Loch Fyne, west coast of Scotland. Aquacult Environ Interact 3:51-63

Aldrin M, Storvik B, Kristoffersen AB, Jansen PA (2013) Space-time modelling of the spread of salmon lice between and within Norwegian marine salmon farms. PLoS ONE 8:e64039

Baxter JM, Boyd IL, Cox M, Donald AE and others (eds) (2011) Scotland's Marine Atlas: information for the national marine plan. Marine Scotland, Edinburgh, available at http://77.68.107.10/MarineAtlas-Complete.pdf

CoGP (2013) A code of good practice for Scottish finfish aquaculture. www.thecodeofgoodpractice.co.uk/

> Costello MJ (2009) The global economic cost of sea lice to the salmonid farming industry. J Fish Dis 32:115-118

Edwards A, Sharples F (1986) Scottish sea lochs: a catalogue. Scottish Marine Biological Association/Nature Conservancy Council, Oban

Gillibrand PA, Turrell WR (1997) The use of simple models in the regulation of the impact of fish farms on water quality in Scottish sea lochs. Aquaculture 159:33-46

> Grant AN (2002) Medicines for sea lice. Pest Manag Sci 58: 521-527

> Jansen PA, Kristoffersen AB, Viljugrein H, Jimenez D, Aldrin M, Stein A (2012) Sea lice as a density-dependent constraint to salmonid farming. Proc R Soc Lond B Biol Sci 279:2330-2338

Kristoffersen AB, Rees EE, Stryn H, Ibarra R, Campisto JL, Revie CW, St-Hilaire S (2013) Understanding sources of sea lice for salmon farms in Chile. Prev Vet Med 111: 165-175

Mayor DJ, Solan M, Martinez I, Murray L, McMillan H, Paton GI, Kilham K (2008) Acute toxicity of some treatments commonly used by the salmon aquaculture industry to Corophium volutator and Hediste diversicolor: whole sediment bioassay tests. Aquaculture 285:102-108

McCulloch CE, Searle SR (2001) Generalised, linear, and mixed models. Wiley, New York, NY

Middlemas SJ, Fryer RJ, Tulett D, Armstrong JD (2013) Relationship between sea lice levels on sea trout and fish farm activity in western Scotland. Fish Manag Ecol 20: 68-74

MSS (Marine Scotland Science) (2013) Locational guidelines for the authorisation of marine fish farms in Scottish waters. Marine Scotland Science, Aberdeen, available at www.scotland.gov.uk/Resource/0044/00441646.pdf

> Murray AG (2011) A simple model to assess for selection for treatment-resistant sea lice. Ecol Modell 222:1854-1862

> Murray AG, Munro LA, Wallace IS, Berx B, Pendrey D, Fraser D, Raynard RS (2010) Epidemiological investigations into the re-emergence and control of an outbreak of infectious salmon anaemia in the Shetland Islands, Scotland. Dis Aquat Org 91:189-200

Murray AG, Amundrud TL, Penston MJ, Pert CC, Middlemas SJ (2011) Abundance and distribution of larval sea lice in Scottish coastal waters. In: Jones S, Beamish R (eds) Salmon lice: an integrated approach to understanding parasite abundance and distribution. Wiley-Blackwell, Chichester, p 51-81

Nelder JA, Wedderburn RWM (1972) Generalized linear models. J R Statist Soc A 135:370-384

> Pike AW, Wadsworth SL (1999) Sealice on salmonids: their biology and control. Adv Parasitol 44:233-337

> Revie CW, Gettinby G, Treasurer JW, Wallace C (2003) Identifying epidemiological risk factors affecting sea lice Lepeophtheirus salmonis abundance on Scottish salmon farms using generalised linear models. Dis Aquat Org 57: 85-95

Salama NKG, Collins CM, Fraser JG, Dunn J, Pert CC, Murray AG, Rabe B (2013) Development and assessment of a biophysical dispersal model for sea lice. J Fish Dis 36: 323-337

Soares S, Green DM, Turnbull JF, Crumlish M, Murray AG (2011) A baseline method for benchmarking mortality losses in Atlantic salmon (Salmo salar) production. Aquaculture 314:7-12

- Treasurer JW (2002) A review of the potential pathogens of sea lice and the application of cleaner fish in biological control. Pest Manag Sci 58:546-558

- Valdes-Donoso P, Mardones FO, Jarpa M, Ulloa M, Carpenter TE, Perez AM (2013) Co-infection patterns of infectious salmon anaemia and sea lice in farmed Atlantic salmon, Salmo salar L., in southern Chile (2007-2009). J Fish Dis 36:353-360

Venables WM, Smith DN (2013) An introduction to R version 3.0.1. R Foundation for Statistical Computing, Vienna, available at http://cran.r-project.org/doc/manuals/r-release/ R-intro.pdf

Willis KJ, Gillibrand PA, Croney CJ, Black KD (2005) Sea lice treatments on salmon farms have no adverse effects on zooplankton communities: a case study. Mar Pollut Bull 50:806-816

Submitted: November 25, 2013; Accepted: March 18, 2014 Proofs received from author(s): May 13, 2014 